\title{
DEVELOPMENT OF DOMESTIC LYOCELL BASED PHENOLIC IMPREGNATED CARBON ABLATOR (PICA-D) FOR FUTURE NASA MISSIONS
}

\author{
Matt Gasch $^{1}$, Kristina Skokova ${ }^{2}$, Mairead Stackpoole ${ }^{1}$, Ethiraj Venkatapathy ${ }^{1}$, Don Ellerby ${ }^{1}$, \\ Frank Milos ${ }^{1}$, Keith Peterson ${ }^{1}$, Dinesh Prabhu ${ }^{2}$, Greg Gonzales ${ }^{2}$, \\ Steve Violette ${ }^{3}$ and Taylor Franklin ${ }^{3}$ \\ ${ }^{1}$ NASA Ames Research Center, Moffett Field, CA 94035 \\ ${ }^{2}$ AMA, NASA Ames Research Center, Moffett Field, CA 94035 \\ ${ }^{3}$ Fiber Materials Inc., Biddeford, ME, 04005
}

Keywords: Domestic, Lyocell, PICA, Ablative TPS 


\begin{abstract}
Phenolic Impregnated Carbon Ablator (PICA) is a low-density ablator that has been used as the planetary entry heatshield for several NASA missions since the late 90's. Its low density and efficient performance characteristics have proven effective for use from Discovery to Flag-ship class missions. The rayon-based carbon precursor raw material used in PICA preform manufacturing has experienced multiple supply chain issues and required replacement and requalification at least twice in the past 25 years, and a third substitution is now needed. Due to the obsolescence of the input foreign rayon fiber source, a new variant of PICA has been developed using a domestic rayon-like fiber source, Lyocell. Results are presented from this effort including fiber conversion, fabrication of tile component and near net shaped heatshield preforms, and conversion to PICA materials. Thermal, mechanical, and representative environment arc-jet tests have been conducted. Initial testing of PICA-Domestic (PICA-D) indicates comparable performance with respect to "heritage" PICA materials and thus PICA-D is expected to be a sustainable solution for future NASA missions.
\end{abstract}

\title{
Introduction
}

PICA, invented in the mid 1990's [1] at NASA Ames Research Center, is the lowest density carbon-phenolic based ablative thermal protection system (TPS) with flight heritage. PICA is composed of a rigid carbon fiber based preform (derived from rayon) that is infused with a porous phenolic matrix. PICA is a relatively straight forward ablative TPS to manufacture and to model its response to the aerothermal entry environment, given that it has a limited number of constituents. Fiber Materials Inc. produces carbon FiberForm ${ }^{\mathrm{TM}}$, a rigid, low density porous carbon foam-like material, using a proprietary process from chopped carbon fibers. The carbon fibers are derived from commercially available rayon by a high temperature conversion process allowing controlled removal of volatiles (cabonization) and graphitization. The PICA process involves infusing the carbon FiberForm ${ }^{\mathrm{TM}}$ with a lightweight phenolic resin matrix. The phenolic resin infusion and curing yields a high surface area phenolic phase filling the void space between filaments resulting in a low conductivity and low density ablative TPS that has proven performance at heat-fluxes approaching $1500 \mathrm{~W} / \mathrm{cm}^{2}$ and stagnation pressures approaching $1 \mathrm{~atm}$.

The timely invention of PICA enabled the Stardust mission [2], the very first mission to bring back samples from outside the Earth-Moon system. During entry, the sample return capsule was protected from the entry environment by a single-piece near-net-shape cast PICA heatshield. OSIRIS-REx, the first US mission to bring back samples from an asteroid (Bennu) to Earth, also uses a single piece PICA heatshield very similar to the Stardust design. In addition to Stardust and OSIRIS-REx, PICA was used as the heatshield material for the Mars Science Lab (MSL) mission, in a tiled configuration. The Mars 2020 mission heatshield design will follow that of MSL using PICA in a tiled arrangement. Based on successful mission use across destinations ranging from Earth return to Mars, PICA has been proposed as the heatshield TPS option for numerous missions including New Frontier and Discovery competed missions, a Lunar Sample Return Misson, and as the backshell TPS for missions to multiple destinations such as Venus and Saturn, where the environments require a carbon-based ablator.

In spite of the fact that PICA only has two constituents and a relatively straightforward process, it has faced multiple supply chain issues. The original PICA was manufactured using FiberForm ${ }^{\mathrm{TM}}$ derived from Liberty rayon (a US based source). Liberty rayon manufacturing was discontinued in the mid 2000s'. Since the FiberForm ${ }^{\mathrm{TM}}$ commercial product line depends on a rayon precursor, 
FMI evaluated an alternate rayon, Sniace, (a Spanish source). When FMI learned that the Sniace rayon used for MSL PICA was discontinued, they acquired a sufficient quantity in anticipation of PICA needs for the Mars 2020 mission. FMI informed NASA of the imminent supply chain issue. NASA then decided to secure the remaining limited quantity of Sniace rayon, convert to carbon and store for future SMD use. In addition, NASA started to evaluate whether Lyocell [3-4] based PICA would be comparable to heritage PICA. FMI is currently working with NASA to establish Lyocell based PICA as a future replacement for "heritage" PICA.

\section{PICA-D Development Plan and Project Scope}

In 2016, NASAs Science Mission Directorate in partnership with the Planetary Science Division (SMD-PSD) funded an effort proposed by NASA Ames to contract with FMI and conduct an exploratory study to procure and convert a small batch of Lyocell rayon into PICA (PICA-D, where $\mathrm{D}$ stands for domestic) and perform limited arc jet and material property testing. The results from these tests were reported in an IEEE paper, and provided high confidence that PICA-D could be a replacement for "heritage" PICA.[5] This initial work on Lyocell-derived PICA was key in informing the viability of Lyocell as a PICA precursor. The next phase of the PICA-D development effort, conducted in 2018-2019, had two objectives: 1) to further characterize the Lyocell derived PICA, maturing it for future mission use and 2) explore expansion of PICAs capabilities.

Objective 1 was to firmly establish PICA-D as a replacement for "heritage" PICA by completing additional property testing and arc jet tests for comparison to "heritage" databases. Tasks involved with objective 1 included:

- Fabrication of 7 billets of PICA-D using the heritage FMI processes;

- Thermal and structural material property testing of PICA-D billets at a range of temperatures to confirm physical properties are comparable to heritage PICA;

- Arcjet testing at multiple arc jet conditions to verify that in-depth temperature response and recession of PICA-D is comparable to heritage PICA. Testing to include wedge and instrumented stagnation coupons;

- (If necessary) Update of the FIAT thermal response model for PICA, utilizing arcjet test data and new material properties of PICA-D.

Objective 2 was to investigate expansion of PICA-D capabilities, both in manufacturing size and performance capabilities, to enable new missions not previously possible with state-of-the-art PICA. To date the Stardust and OSIRIS REx missions used the same single piece PICA heatshield design which was $0.8-\mathrm{m}$ diameter, while a number of previous missions have desired a larger single piece heatshield. In addition, typically PICAs performance envelops have been constrained to ones previously flown; however, there have been missions that desire to fly PICA at more aggressive entry environments and there is limited ground-based test data to indicate that PICA has capability beyond what Stardust flew. Tasks involved with Objective 2 included:

- Manufacturing scale-up of a single piece PICA-D aeroshell from $0.8 \mathrm{~m}$ to $1.5 \mathrm{~m}$;

- Characterization of fiber alignment and FiberForm uniformity of $1.5 \mathrm{~m}$ aeroshell;

- Establishment of expanded thermal performance of PICA-D via arcjet testing at conditions (heat flux, pressure, shear) beyond which PICA has previously flown. 


\section{Objective 1 - PICA-D Replacement Testing}

Mechanical and Thermal Testing

To support property testing seven Lyocell-based FiberForm ${ }^{\mathrm{TM}}$ billets were fabricated using the general specification for PICA tile components, incorporating the Lyocell-based fiber precursor materials in place of rayon precursors. The billets were designated as LI-12 to LI-18. From these billets, five were selected for phenolic infusion. PICA-D billets LI-17 and -18 were selected for property testing to scope of which is shown in Tables 1 and 2, and results compared to heritage baseline PICA material databases and Lot Acceptance Testing (LAT) from MSL and Mars 2020. Some testing on FiberForm alone was also conducted and compared to previous FiberForm data.

Table 1. PICA-D mechanical property test matrix and sample count

\begin{tabular}{|c|c|c|c|c|}
\hline \multirow{2}{*}{ Test Type } & \multicolumn{3}{|c|}{ Virgin Property Testing } & $\begin{array}{c}\text { Fiberform } \\
\text { Property Testing }\end{array}$ \\
\cline { 2 - 5 } & $-250^{\circ} \mathrm{F}$ & $\mathrm{RT}$ & $350^{\circ} \mathrm{F}$ & $\mathrm{RT}$ \\
\hline IP tension & 3 & 10 & 3 & 4 \\
\hline TTT Tension & 3 & 10 & 3 & 4 \\
\hline IP Compression & 3 & 3 & 3 & \\
\hline TTT Compression & 3 & 3 & 3 & \\
\hline IP Shear & 3 & 3 & 3 & 4 \\
\hline Transverse Shear & 3 & 10 & 3 & 4 \\
\hline IP CTE & \multicolumn{5}{|c|}{2} & 2 \\
\hline TTT CTE & 2 & 2 \\
\hline
\end{tabular}

Table 2. PICA-D thermal property test matrix and sample count.

\begin{tabular}{|c|c|c|}
\hline \multirow{2}{*}{ Test Type } & \multicolumn{2}{|c|}{ Virgin Property Testing } \\
\cline { 2 - 3 } & $100^{\circ} \mathrm{F}$ & $350^{\circ} \mathrm{F}$ \\
\hline TTT Conductivity & 2 & 2 \\
\hline IP Conductivity & 2 & 2 \\
\hline
\end{tabular}

Tension testing of PICA material complied with ASTM E-4, "Verification of Testing Machines"; ASTM E-83, "Verification and Classification of Extensometers"; ASTM D 1623, Type B, "Standard Test Method for Tensile and Tensile Adhesion Properties of Rigid Cellular Plastics"; and FMI IPOS 08-02-04 Part M Revision A, "In-Plane and Thru-Thickness Orientation Tensile Testing Procedure for FMI PICA Materials". Test specimens were bonded to T6-6061 aluminum loading blocks using epoxy resin in an alignment fixture, and following cure were subsequently placed into the test equipment. Test equipment included an Instron Model 1115 Electromechanical 10,000 lb capacity test machine; Instron model 2511-301 1,000 lb. load cell; MTS model \# 63259C-01 Elevated Temperature Contacting Extensometry System; and data acquisition computer system with National Instruments LabVIEW 2011 software.

As shown in Figure 1, the PICA-D results are very comparable LAT results for production heritage PICA. No anomalies were identified in the minimum values of tension strength, variance of tension strength, or the other measurements with respect to heritage PICA test results. 


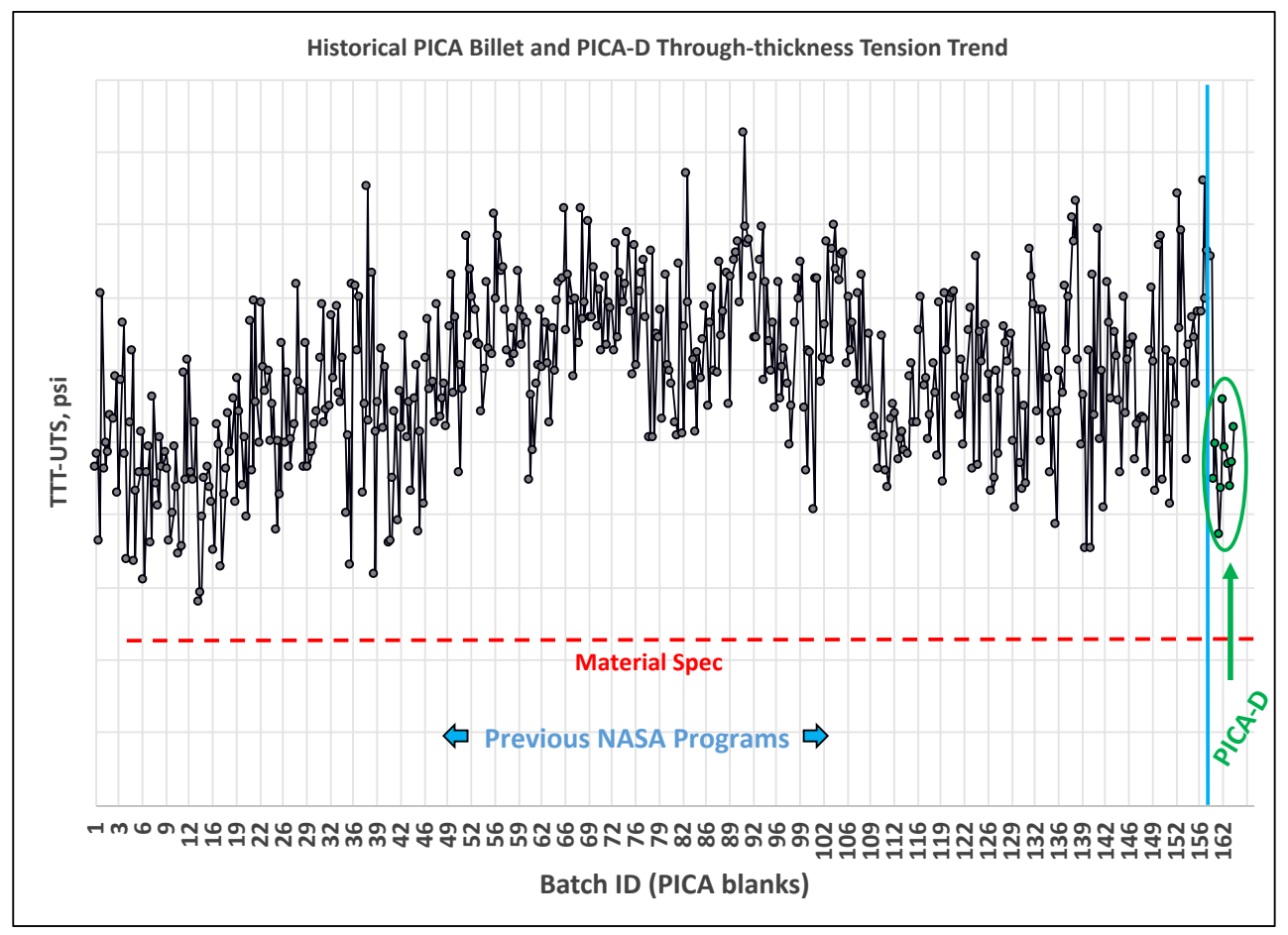

Figure 1. Heritage PICA and PICA-D through-the-thickness strength trend across various NASA programs.

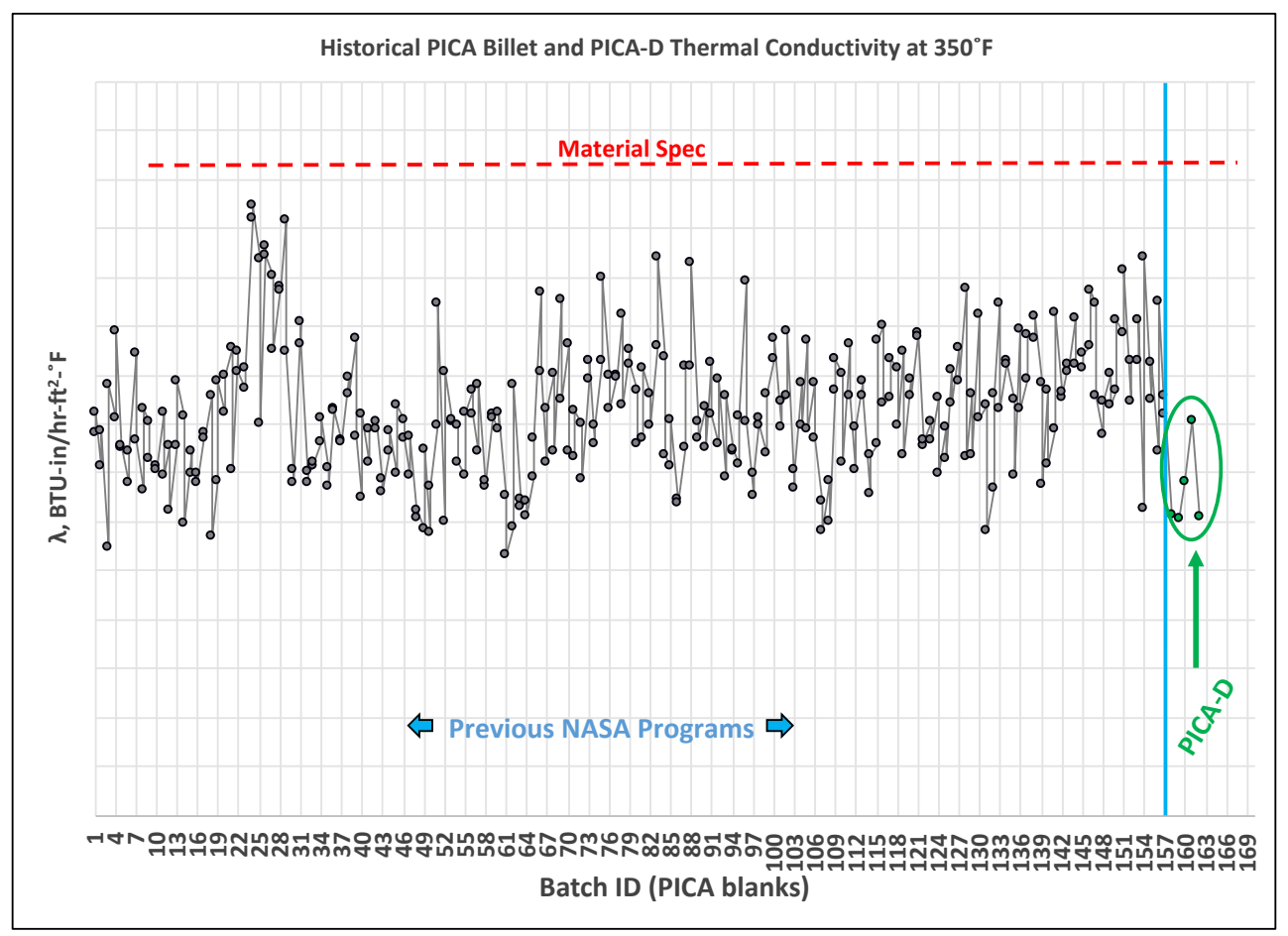

Figure 2. Heritage PICA and PICA-D thermal conductivity trend across various NASA programs. 
Thermal conductivity measurements were performed by the comparative rod analysis method (ASTM E1225, "Standard Test Method for Thermal Conductivity of Solids by Means of the Guarded-Comparative-Longitudinal Heat Flow Technique") and FMI IPOS 08-08-20, "Thermal Conductivity Test Procedure: Comparative Flat Slab Method". The test specimens were instrumented with thermocouples in grooves on the top and bottom faces and were mounted between two metering samples of the reference material (NIST standard). This stack was longitudinally positioned between a set of top and bottom heaters and associated heat sinks. A thermal guard heater was placed around the test stack to minimize radial heat flow, and insulation was installed to surround the setup. The entire stack was enclosed by a glass bell jar, and then evacuated and backfilled with the test gas, $0.2 \mathrm{~atm}$ argon. Measurements and calculations were conducted in accordance with ASTM E1225. As shown in Figure 2, the PICA-D conductivity data exhibits very comparable variation in results when compared heritage rayon derived PICA.

Arc jet testing in support of Objective 1, was first performed in early 2017 using Ames Research Center's Interaction Heating Facility (IHF) and Aerodynamic Heating Facility (AHF) as reported in Reference 5. Those initial tests provided the first confirmation that PICA-D had comparable thermal response and centerline recession to heritage MSL PICA. The current study had an expanded arcjet test campaign with 3 test approaches that are shown in Figure 3. The first approach was to duplicate the work done in early 2017 using 4-inch diameter stagnation coupons and to expand on PICA-D heat flux performance limits with the addition of 2-inch diameter coupons. The second and third approaches were planned as a means of probing the performance limits (heat flux, pressure and shear) of PICA-D using alternative arcjet coupon designs.

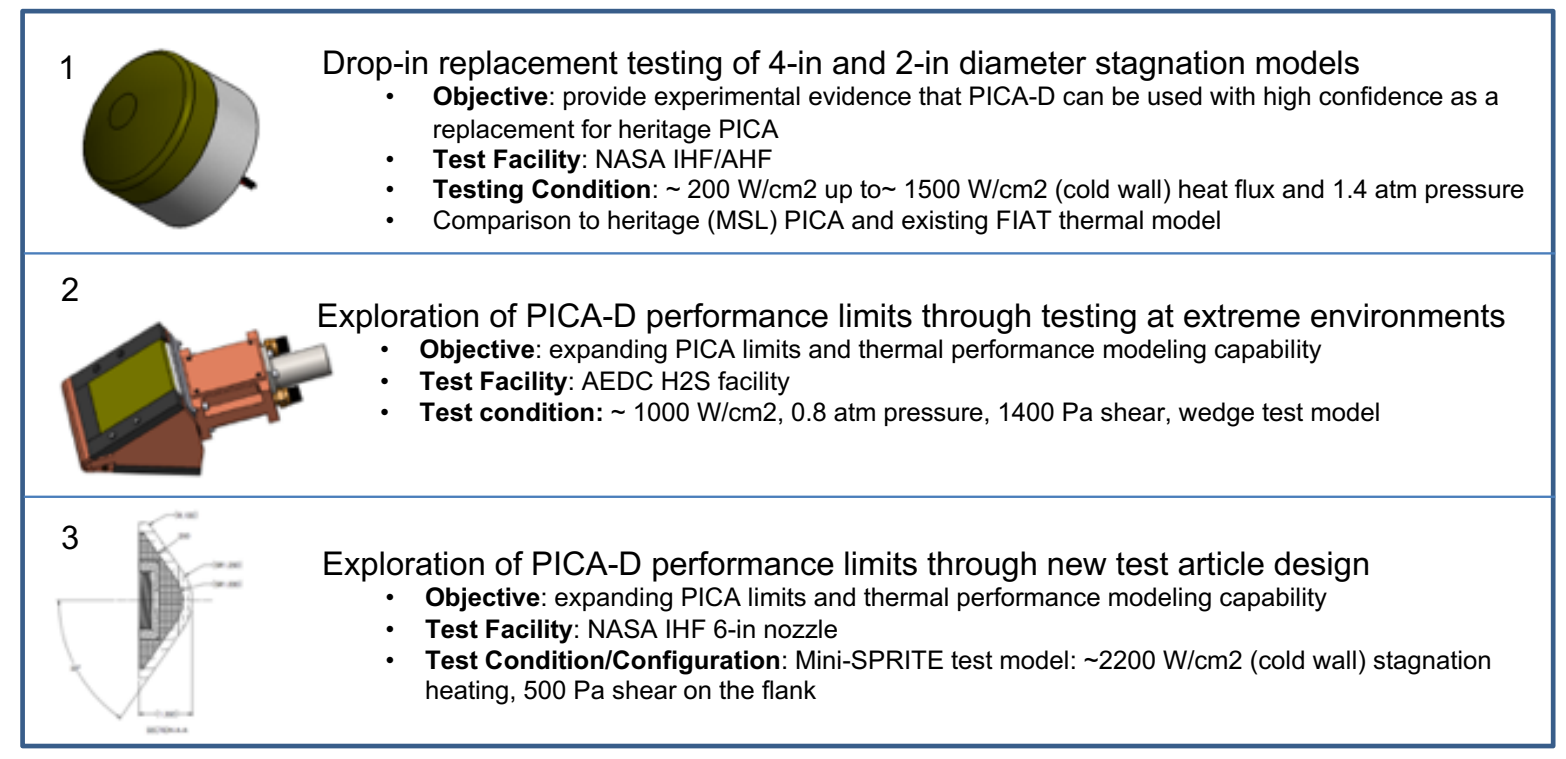

Figure 3. Arcjet model configurations for current study.

As of May 2019, arcjet facility availability at both NASA and the AEDC arcjets has delayed completion of the arcjet campaign for PICA-D until late 2019/early 2020. Fortunately, before the facility delays one wedge test of PICA-D was completed in support of Dragonfly Phase A study. PICA-D built 2 wedge shear models with RTV seams for testing in a nitrogen environment. Prior 
to this test, PICA with RTV seams had only been tested in air under the MSL and Orion programs. The wedge test in Nitrogen in support of Dragonfly Phase A was planned around 2 conditions:

- Condition 1: Heat Flux $=136 \mathrm{~W} / \mathrm{cm} 2$ Pressure $=14 \mathrm{kPa}$

- Condition 2: Heat Flux $=256 \mathrm{~W} / \mathrm{cm} 2$ Pressure $=19 \mathrm{kPa}$

In November 2018, the first of two models were successfully tested at Condition 1 in theTP3 arc jet facility with 7.5in nozzle, Figure 4. There was very little recession of the PICA-D material in the nitrogen environment and no cracking or fencing of the RTV seams was observed - a good indication that Lyocell-derived PICA and a heritage MSL PICA have comparable performance, in both oxygen and nitrogen.

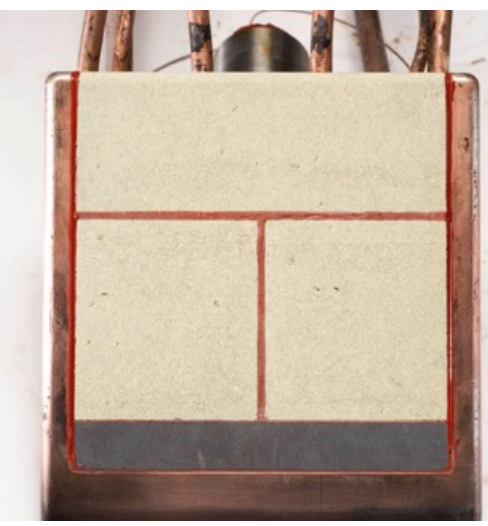

Pre-test Photo

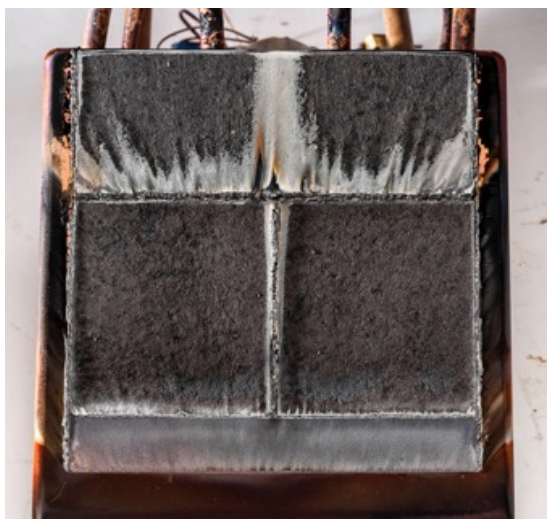

Post-test Condition 1

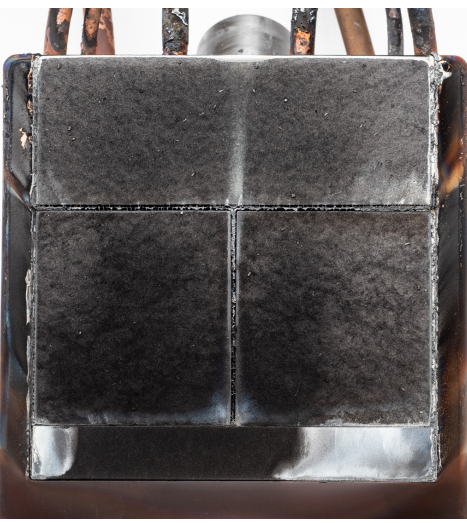

Post-test Condition 2

Figure 4. Pre and post-test PICA-D wedge test models with an RTV gap filler.

\section{Objective 2 - PICA-D Expanded Capability and Scale-Up}

Finally, in support of investigating the capability of PICA-D to enable new missions not previously possible with state-of-the-art PICA fabrication methods or previous flight environments, FMI was tasked by NASA to scale-up the single piece aeroshell from $0.8-\mathrm{m}$ to $1.5-\mathrm{m}$ diameter. In order to complete this task, FMI developed the tooling required to support the fabrication of a 1.5-m diameter, net-shaped FiberForm ${ }^{\mathrm{TM}}$ heatshield casting. By December 2018, FMI completed the fabrication of 4 units, one of which is shown in Figure 5. One of the 4 units is currently being destructively evaluated to measure density gradient across 5 sections that were cut from five evenly-spaced cores from apex to shoulder. Each of the 5 cores will be sectioned into 4 top-tobottom sections (20 density gradient measurements total). One of the net-shaped units recently completed PICA infusion and is being held with the other two FiberForm ${ }^{\mathrm{TM}}$ units for further analysis. 


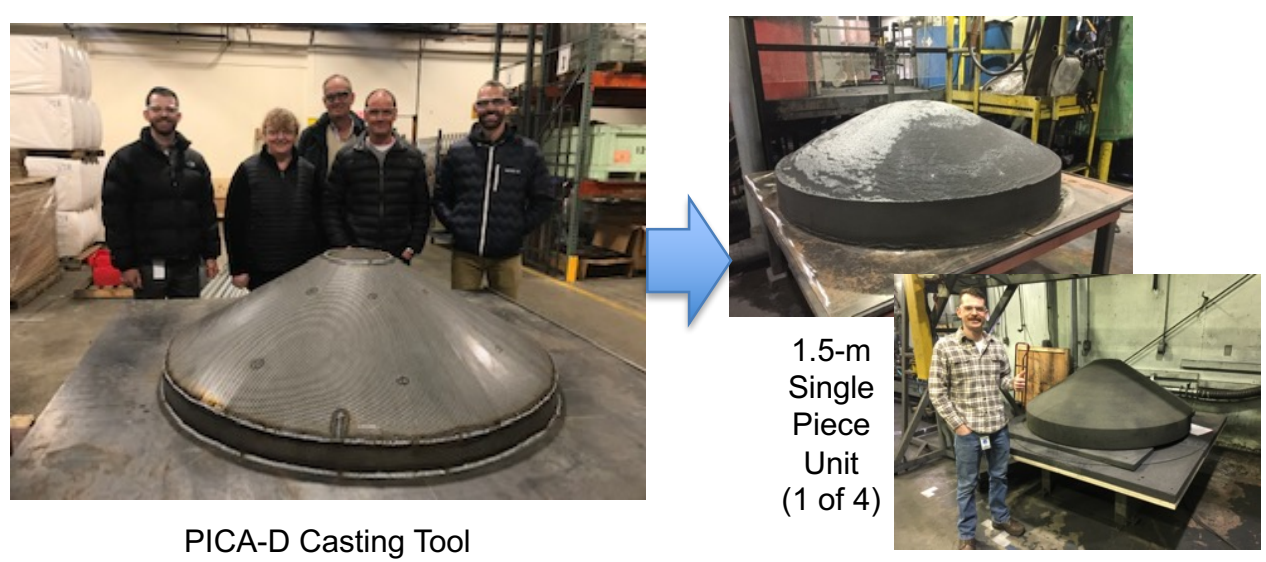

Figure 5. Near-net-shape single-piece Lyocell-based aeroshell scaled up to 1.5-m diameter.

\section{$\underline{\text { Summary }}$}

PICA manufactured from a Lyocell carbon fiber precursor, a domestic rayon alternative, has proven to have comparable performance to "heritage" material and FMI has demonstrated manufacturing PICA-D in a billet form as well as a net shape cast unit. Lyocell derived PICA has successfully been fabricated within the density specification of standard (heritage) PICA and preliminary arc-jet testing on a limited number of coupons, spanning the anticipated low to high potential application range for PICA indicate that Lyocell PICA behavior is comparable in both recession and thermal response to heritage MSL material. Mechanical and thermal properties are also in family with "heritage" rayon PICA. From these results, all indications are that lyocell PICA can successfully be used as a replacement for future NASA mission needs. Since Lyocell is manufactured in the US in very large quantities and the need is in the commercial sector, Lyocell based PICA is anticipated to be a sustainable source for future mission needs. Finally, to enable new missions not previously possible with state-of-the-art PICA, FMI successfully demonstrated the ability to scale-up the single piece aeroshell from $0.8-\mathrm{m}$ to $1.5-\mathrm{m}$ diameter. Four 1.5 -meter net shape units were fabricated in 2018 and one was recently put through the PICA process and is awaiting further analysis in 2019.

\section{Acknowledgements}

The authors thank NASAs Space Mission Directorate Planetary Science Division for funding this project.

\section{$\underline{\text { References }}$}

1. Tran, H.K., "Phenolic Impregnated Carbon Ablators (PICA) for Discovery Class Missions", AIAA Paper 96-1911, June 1996.

2. Wilcockson, W., "Stardust Sample Return Capsule design experience", 7th AIAA/ASME Joint Thermophysics and Heat Transfer Conference, AIAA paper \# 2854, 1998.

3. Lyocell (n.d.) In How Products are Made. Retrieved on Oct 11th 2017, from http://www.madehow.com/Volume-5/Lyocell.html

4. Lenzing, (n.d.) In Business Insider. Retrieved on Oct 11th 2017, from http://www.businessinsider.com/how-tencel-compares-to-cotton-2015-9 https://www.youtube.com/watch?time_continue $=450 \& v=X 6 w p 1 S T 2 J a s$

5. Stackpoole, M, Venkatapathy, E. and Violette, S., "Sustaining PICA for future NASA Robotic Science Missions including NF-4 and Discovery," IEEE, Vol. 10.1109/AERO, pp. 1-7, 2018. 